First publ. in: Zeitschrift für Physik / B, 98 (1995), 3, pp. 303-309

\title{
Ions at helium interfaces
}

\author{
Pau] Leiderer \\ Fakulıät für Physik, Universität Konstanz, D-78434 Konstanz, Germany
}

\begin{abstract}
The boundaries between diflerent phases of condensed helium provide an interesting testing ground for studying ions in a quantum matter matrix. Here we consider the simplest positive and negative jons in helium - snowballs and electron bubbles, respectively - being trapped at the liquid-liquid interface of phaseseparated ${ }^{3} \mathrm{He}-{ }^{4} \mathrm{He}$ mixtures and at the liquid-solid interlace of ${ }^{4} \mathrm{He}$. A comparison of experimental results for the trapping with predictions of the snowball and the bubble models shows that the models are in qualitative accord with the observations, but disagree in detail. It is suggested to use such studies for refinements of the ion models. In addition multielectron bubbles ( = mesoscopic ions) and electrons on helium films are briefly discussed.
\end{abstract}

\section{Introduction}

The condensed phases of helium provide a variety of very clean, well-defined interfaces which in the past have been studied both for their own sake and as model systems for condensed matter in general. The interface between liquid and solid $\mathrm{He}$, e.g., is one of the best understood systems displaying a roughening transition, and subtle but important details have been measured there [1], which in other systems so far have not been experimentally accessible. Likewise, liquid mixtures of the two stable helium isotopes ${ }^{3} \mathrm{He}$ and ${ }^{4} \mathrm{He}$ in the vicinity of their consolute critica] point (at a temperature $T_{1}=0.867 \mathrm{~K}$ and a ${ }^{3} \mathrm{He}$ concentration $x_{q}=0.67$ ) represent one of the most ideal and best-studied systems exhibiting a higher order (in this case tri-jcritical point, and the interface between the two coexisting helium phases - a superfluid ${ }^{4} \mathrm{He}$-rich and a normal ${ }^{3}$ He-rich phase - has been the topic of detajled investigations, in particular with respect to its critical behavior [2]. Moreover, the most easily accessible helium interface, namely the "free" surface between liquid and gas, has also been studied in a number of experiments.
In the course of these investigations ions have played an important role for several reasons:

j) ions can be used as very sensitive and convenient probes not only for bulk, but in particular also for interfacial and surface properties;

ii) vice versa, interfaces can be used to test models for the various ion species in liquid and solid helium;

iii) the ions, being charged particles, form novel 2-dimensjonal Coulomb systems which due to their interaction have interesting collective properties.

Whereas the first aspect, ions as an interfacial and surface probe, has been reviewed already in several articles [3] and will therefore not be considered here further, there exist haroly any publications on the exploitation of belium interfaces for testing models of the ion structures. This will hence be the central topic of the present paper. The last aspect, phenomena arising from the Coulomb interaction between charges at the interface, is treated in the contribution by W.F. Vinen in this volume and will only be shortly addressed at the end of this paper.

The ions we shall deal witb are the two types that are most easily generated in liquid helium [4], e.g. by irradiation with energetic particles: The negative ion in this case simply consists of an electron inside a spherical cavity in the liquid, the so-called electron bubble, wbich has a diameter of about $35 \AA$ and is stabilized essentially by the equilibrium between the forces due to surface tension (pointing inward) and zero point motion of the electron (pointing outward). Positive $\mathrm{He}$ ions in liquid belium, on the other hand, are considered as solid "snowballs", which form under the influence of the electrostrictive pressure due to the central charge of the snowball, and have a diameter around $15 \AA$.

In spite of these - in principle - simple pictures we shal? see that the behavior of these ions at interfaces cannot be described in a quantiative way, if the crude models existing for bubbles and snowballs are applied. Such discrepancies, derived from the trapping of ions at interfaces, have been pointed out already one and a hall decades ago $[5,6]$. Since then, however, considerable progress has 
been made in experimental techniques, one of the most spectacular being the application of laser speciroscopy, as evidenced in various contributions to this symposium. These new experiments certainly will give rise to more refined versions of the ion models, and existing results for ions at interfaces can then serve as a sensitive testing ground for these models. Moreover, it has been shown [3] that it is possible to accumulate considerable ion densities $\left(\sim 10^{9} \mathrm{~cm}^{-2}\right)$ at the interlaces, hence it should be possible to study the jons directly in this environment by spectroscopic means.

In the following we sball treat in chapter 2 the rapping of ions at the interface between the coexiscing ${ }^{3} \mathrm{He}$ and ${ }^{4} \mathrm{He}$-rich phases of liquid ${ }^{3} \mathrm{He}-{ }^{4} \mathrm{He}$ mixtures near the tricritical point. Chapter 3 deals with ions at the interface between liquid and crystalline ${ }^{4} \mathrm{He}$. Finally, in chapter 4 charges at the liquid-gas interface are considered, mainly the mesoscopically sized multielectron bubbles and electrons on He films.

\section{Ions at the liquid-liquid interface of ${ }^{3} \mathrm{He}-{ }^{4} \mathrm{He}$ mixtures}

As already mentioned, a ${ }^{3} \mathrm{He}-{ }^{4} \mathrm{He}$ mixture with concentralion $x_{1}$ is phase-separated below the tricritical temperature, with a ${ }^{3} \mathrm{He}$-rich normal phase floating on $10 \mathrm{p}$ of a ${ }^{3} \mathrm{He}$-rich superfluid one. The boundary between the two coexisting phases undergoes a critical softening near $T$, which manifests itself in a rapid decrease of the interfacial tension $\sigma_{1} \propto\left(T_{1}-T\right)^{2}[2]$. The motion of the ions is strongly influenced by this interface: For electron bubbles it has been observed that at temperatures far below $T_{1}$, where $\sigma_{i}$ is large, the charges do not penetrate from the upper jnto the lower phase due to a high energy barrier at the phase boundary [7]. The barrier results mainly from the lower surface tension of the ${ }^{3} \mathrm{He}$-rich phase and has been estimated to be $\Delta W \approx 220 \mathrm{~K}$ for temperatures below $0.3 \mathrm{~K}$. Thus electron bubbles can be trapped above the interface at a distance of about the bubble radius. On approaching the tricritical point the two coexisting liquid phases become more and more similar, and the barrier height decreases rapidly. Eventually, when $a W$ becomes comparable to $k_{B} T$, the ions will be able 10 pass the barrier by thermal acrivation.

For positive He "snowballs" the interface was shown 10 represent a barrier in the reverse direction, from the lower to the upper phase, because the positive jon energy (dominated by the polarizability) is lower in the superfuid phase [5]. Thus a layer of such snowballs can be trapped just below' the interface when an appropriate bolding field is applied. (Polarization effects also provide a potential barrier for the negative ions going from the denser to the less dense phase, similar to the situation at the free ${ }^{4} \mathrm{He}$ surlace [8], bence ar low enough temperatures bubbles can also be trapped below the ${ }^{3} \mathrm{He}-{ }^{4} \mathrm{He}$ interface). Again, sufficiently close to the tricritical point tbe barrier beight becomes comparable to $k_{B} T$, and also the positive ions will pass into the other phase.

Since the energy barrier $\Delta W$ depends on the structure of the ions, a determination of the characteristic trapping lime $\tau$ at the interface (which is essentially determined by $\Delta W$ ) can serve as a sensitive consistency check for the models used to describe the ion structure. Measurements of the trapping rimes have been carried out [5] either by following directly the decay of the current after charging the interface or by optically measuring the deformation of the interface caused by the electrostatic pressure of the trapped ion pool (see Fig. 1). Results for $\tau$ in the vicinity of the tricritical point are shown in Fig. 2a for positive and in $2 b$ for negative ions as a function of temperature. Obviously the trapping time varies quite rapidly witb temperature, so that the range of $\tau$ which is easily accessible - about I to $1000 \mathrm{~s}$ for the two experimental techniques mentioned above - restricted the measurements to a temperatuse interval $T_{1}-T$ from 70 Lo $90 \mathrm{mK}$. In addition to the propounced temperature dependence there exists also a variation of the absolute value of $\tau$ with the applied electric holding field $E$. For both $k$ inds of ions $\tau$ decreases as $E$ is raised, which qualizatively is the expected dependence. Quite unexpectedly, however, both the absolute value and the temperature dependence of : for positive and negative jons are very similar. By contrast, the existing snowball and bubble models suggest very different behaviors:

i) for negative ions one can estimate the energy barrier $\Delta W$ by considering the main contributions to the bubble energy

$$
\begin{aligned}
W= & h^{2} \pi^{2} /\left[2 m R^{2}\left(1+h /\left(R^{2} 2 m V\right)^{1 / 2}\right)^{2}\right]+4 \pi R^{2} \sigma \\
& +(4 \pi / 3) R^{3} p-e^{2}(\varepsilon-1) / 2 \varepsilon R .
\end{aligned}
$$

resulting from the energy of an electron in a spherical potential well of depth $V$ and radius $R_{-}$, from the surface tension $\sigma$, the hydrostatic pressure $p$ and the polarisation of the surrounding medium with a dielectric constant $\varepsilon$. A comparison of these contributions for the ${ }^{3} \mathrm{He}$ - and the ${ }^{4} \mathrm{He}$ - rich phase shows that onjy a relatively small energy barrier on the order of $2 \mathrm{~K}$ should exist at a temperature $T_{t}-T=80 \mathrm{mK}$.

ii) for positive ions, an estimate for $\Delta W$ can be obtained by taking into account the polarisation of the liquid surrounding the snowball:

$W=W_{\text {core }}-\left(e^{2} / R_{+}\right)\left(\varepsilon_{3.4}-1\right) / 2 \varepsilon_{3.4}$

where the energy $W_{\text {core }}$ contains the energy of the snowball itself and the contribution of the liquid-solid surface tension (the iadices refer 10 the ${ }^{4} \mathrm{He}$ - and ${ }^{3} \mathrm{He}$ - rich phase. respectively). If we assume for simplicity that the internal snowball structure does not change when passing from one phase to the other, we obtain for the difference of the positive ion energies

$W_{4}-W_{3}=-\left(e^{2} / R_{+}\right)\left(\varepsilon_{4}-\varepsilon_{3}\right) / 2 \varepsilon_{3} \varepsilon_{4}$

In this case the value calculated for the energy barrier $\Delta W$ is $40 \mathrm{~K}$ at a temperature $T_{1}-T=80 \mathrm{mK}$, a factor of 20 higher than for negative ions. Since $\varepsilon_{4}-\varepsilon_{3}$ varies linearly with $T_{1}-T$ one expecis a dependence

$\tau \propto \exp \left[\left(T_{1}-T\right) / k_{g} T\right]$

Indeed, an exponential relationship of this form, indicated by the straight lines in Fig. $2 \mathrm{a}$, is in accord with the 


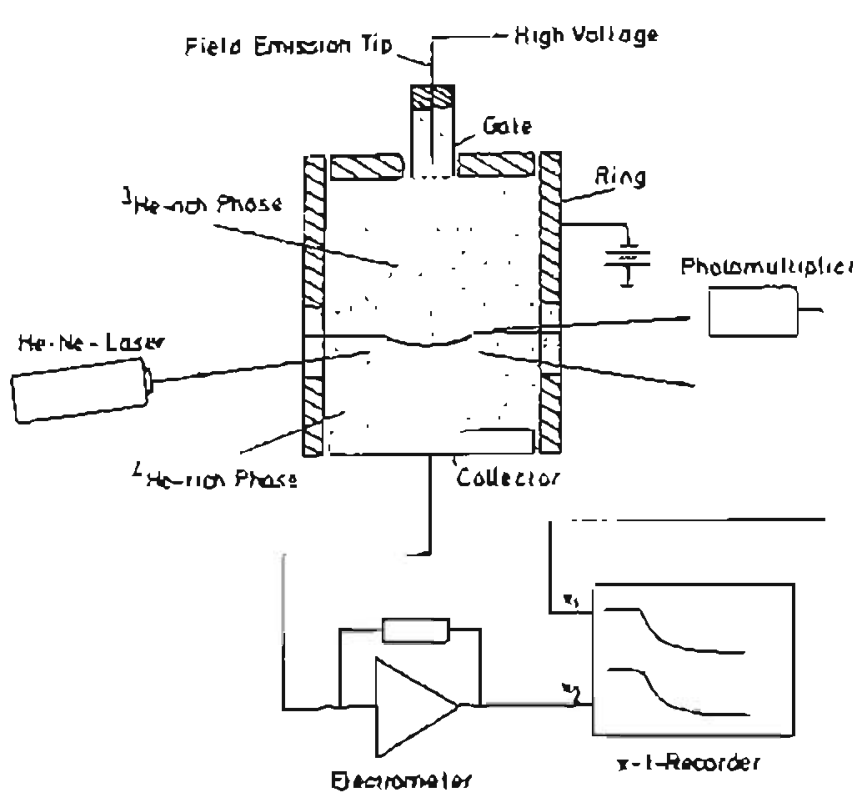

Fig. 1. Experimerial set-up for measurements of the uapping (ime of negative ions when the ion source (here a feld emission lip) is swiched off, an exponennal docay of both the collector current and the light intensily ai die phocomultiplier is observed. The ring is charged such that loss of zons to the wall is prevented. For positive ions ihe sample cell was invertad. and a radioaclive source was used (ailer [S])

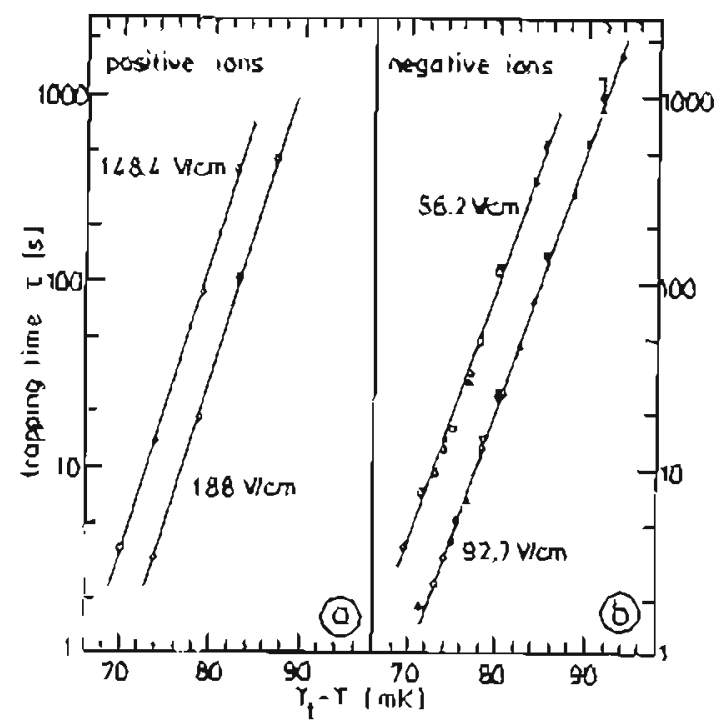

Fig. 2 Trapping ime $\mathrm{r}$ of positive and negative ions a the interiace of a phase separaced liquid ${ }^{3} \mathrm{He}-{ }^{4} \mathrm{He}$ mixcure in the vicinity of the tricrivical temperature $T,=0.867 \mathrm{~K}$ Electrical holding fields are indicared. Open and elosed circles refer 10 electrical and optical measuremenis (soe $\mathrm{F}(\mathrm{g}, \mathrm{l})$

experimental data. Yet the model cannot fully account for the observed trapping times of the posilive ions, because the theoretical value of the coefficient $b$ and heoce the calculaced absolute value of $\Delta W$ is about twice as large as derived from tbe daca in Fig. $2 a$.
For negaluve jons, on the other hand, the theoretical predicuon for $\triangle W$, as calculated from (l), is smaller ihan the experimental value. The disagreement in tbe absolute value in this case even amounis lo nearly one order of magnilude.

Since the expermental uncertainty in $\mathrm{r}$ is well below these discrepancies, the simple ion riodels used here are obviously insufficient to accovnc for a quanlicalive descrlpoion. and more refined approaches appear to be neessary. One might hope that improvements based on the receni progress on ion studies could help to solve this puzzle. In this coniext the measured dependence of the irappiog time on the holding field $E$ (Fig. $\sigma$ is [5]), which so far is also lacking a guanticative intcrprecacion, might be a valuable check ol more sophisticated models.

\section{Ions at the liquid-solid interface of " $\mathrm{He}$}

It is known from a number of experiments that the formation of electron bubbles is not restricted to the liquid phase, but that this kind of negalive ions also exists in solid $\mathrm{He}[9]$. Usiog a calculation similar co (I) the bubole energy in solid "He al the melling pressure can be essimaled to be about $200 \mathrm{~K}$ higher than in the coexisting liquid phase [10]. Therefore it should be gossible to trap electron bubbles al the liquid-solid inicriacc. Experimentally it has been demonseraced that this is indeed the case; actually the trapped ion pool has been used in various experimenis, e.g. 10 determine the growib coefficient of $\mathrm{He}$ crystais [11]. Nevertheless, (he delails of the bubble structure al the interface are iar from being clear: If an electron bubble is pulled against the liquid-solid interface from the liquid side by ao extemal electric field and is hence in contact with the crysial, its surface is parlly liquid and partly solid (Fig. 3). Noshing is known to dale aboui details of the bubble shape in such an anisotropic environment. As for tbe liquid-liquid snierlace discussed belore the spectroscopy of bubbles trapoed on solid helium appears as a promising cool co shed light on this peculiar sysicm.

For positive ions at the liquid-solid interlace the knowledge is even more sparse. It is not clear, e,g. whether they are irapped at all at this boundary when approaching the crystal surface from the liquid phase. At first glance one might expect that the snowballs, due to their soird core, can easily penersate from the liquid side iaco the crystal. However, the structure of the snowball is expected to be incompatible with the enystal structure of hcp ${ }^{4} \mathrm{He}$. Therefore one mighc have a large angle of contacl bel ween the surfaces of the soowball and the crysiat, just as for "YHe crystals in contacl with the disordered solid He layer covering "usual" sample cell walls [12]. This pbenomenon of incomplete welling between ordered and disordered solid $\mathrm{He}$ should give nise 10 a surface barrier for the snowball at the liquid-solid interlace. Yel difiusion processes in the contact region might locally rearrange the $\mathrm{He}$ a Loms. as for the dritt of the snowballs in the erystalline phase under the infivence of an excemal electric field [13], so that upon closer investigation the wetting argument mighe not hold. In fact, preliminary measusemen s scem 10 indicate that snowballs do enter the crystal from the liquad 


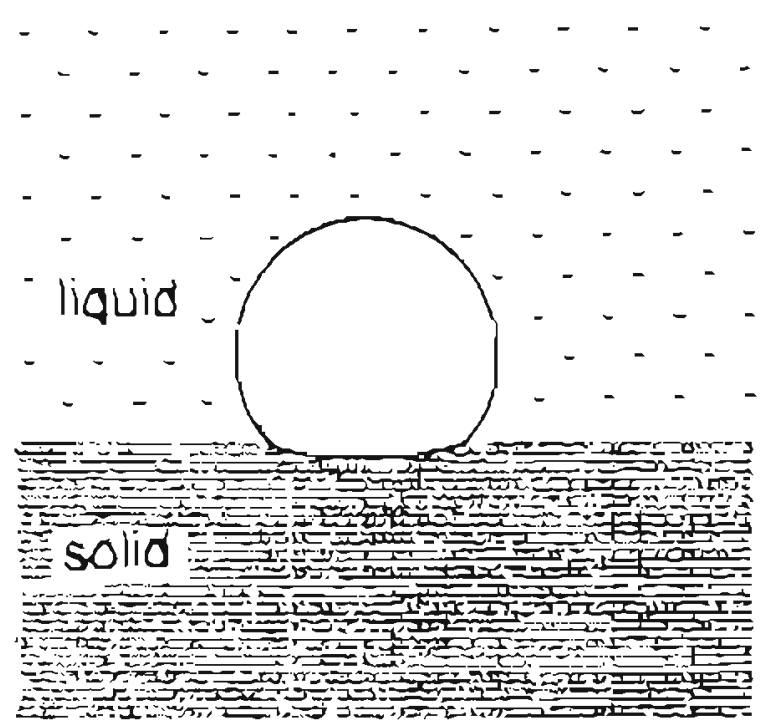

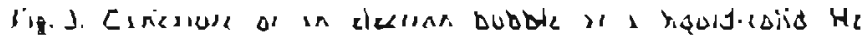
lolellise

ohsse (14). bus more conclusive expenments dre required lor a definle antwer.

\section{s Elemoos 1 ibe liquid - gas iarcriace}

In ihis chaples ue cansidel clecerans irapped obote the suslace oi liquad Hc, Heace we are nal really ocaling wilh ions bill with quasi-fere clecirani, meving parallel is ihe ivelace in it. poleninz) well rciuling (rom ibc iuperposi.

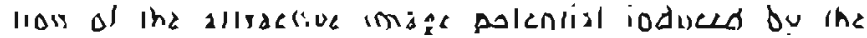
clicirons in ine diclecurtic iubsialc (ncljum). ine exiernal ileiroliswe palcnlial which provides chalge neullalisy of irewhole sysicm, and the chari iange Paulirepulsian sue io ide elosed cliciran shell al inc He scoms. The surlece siake clccisons ihus Sam a iwa-dimicnsional Coularrb

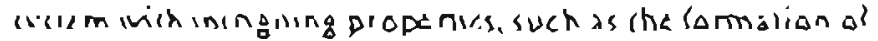
a colrd "Wignes crysial" phase al law cndugh lomger. aives $[1 \leq]$

since the electroms, under the induence of the $4 x^{\text {. }}$

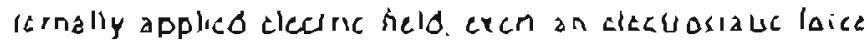
upon the He. Ike liquid suride is ilighely deplesed in ithe icgion of the elceiron Dool. As ite elaclion densily as taled, this depression increses in dealh unlil toxlly ihe surdde undergoes an eleciradjoradyramic (eho) iniladil. ily. where i he elecirans Demeirale inla ihe liquid in ithe

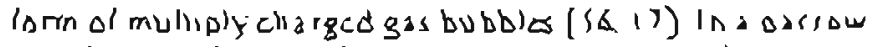

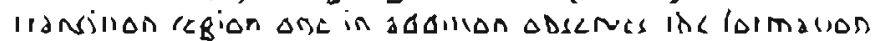

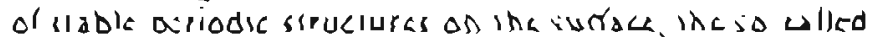
dimole laglece, which resulis lram a sall mads in the sacelium of curiace axcuranans (ripplone) in the pizelne ol ciarager [18]

\section{6) Mubielezoron susbles}

The mulli:leciran bubbles whis d atc generaicd dumng ibe

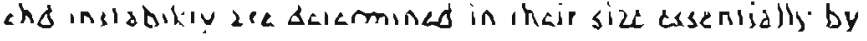

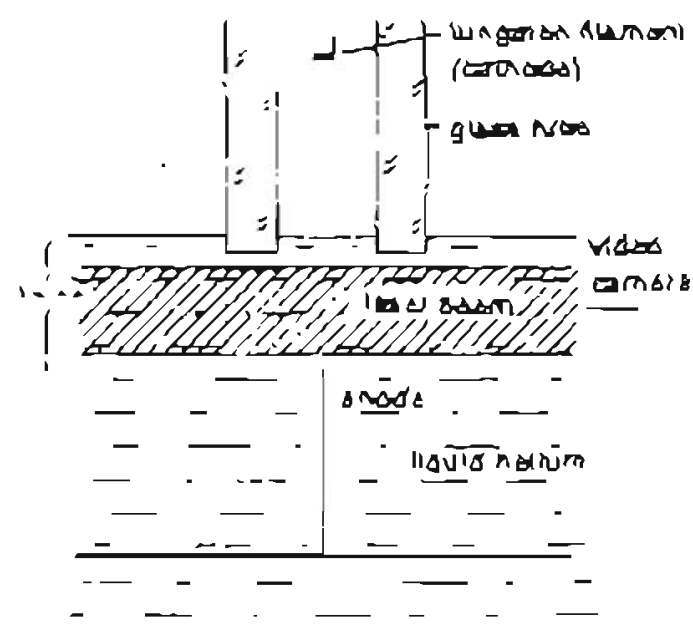

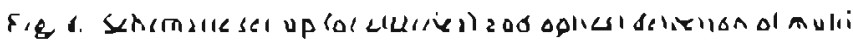

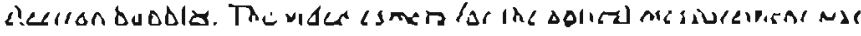

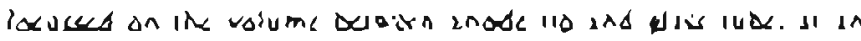

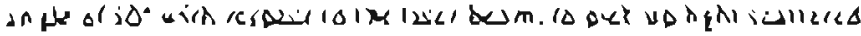

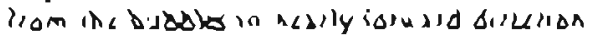

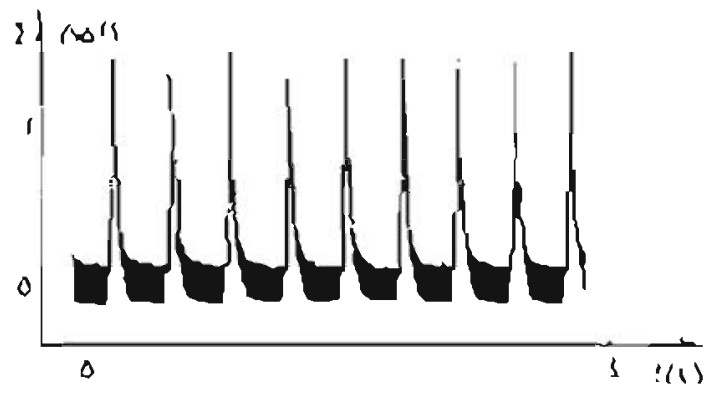

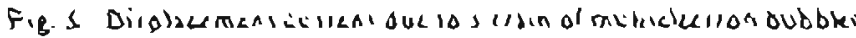

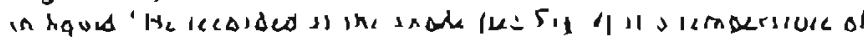

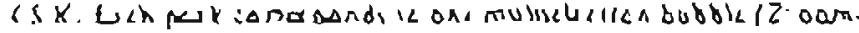

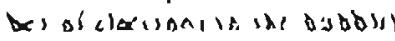

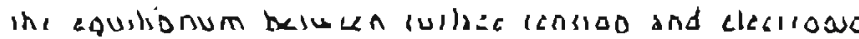

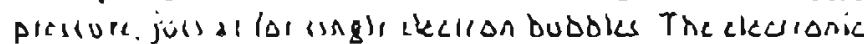
leim nal is anminaled by ibe musal Coulomb lepulisan al ihe elecilane laceed al ine innel surlace al he bubble a (yous) buoble charge is $10 \mathrm{me} 10^{4} \mathrm{elem}$ con. iani (AJiall. ihe carieiponding bubtle diameler seleid) len un $\mid 1)$

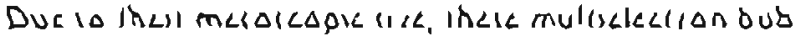

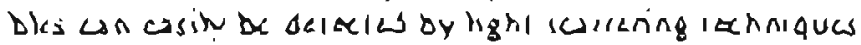
Wish the sel.ug kehemalically ite:ched in Fig a 11 eas alsa possible 10 genciale lcguldt llains al aubblas. ss sown in Fig \& Ercleed dy incll moron iklaugh the iavid the bubbles crhibil p/anaunced acillilialli

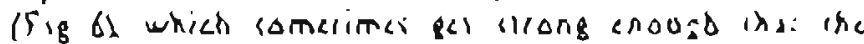
butble andelgoes " Caulama erplasian" ana scpaldics inio lwa smillel lo stmenll

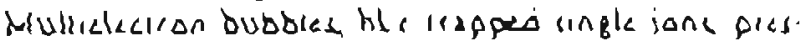
ene many open os buleme 'cgarding thele behjuiot a: inier lacal Even ihcel llablly al inientacel hal rol yel deen investladled. bul enc Tighl im.gin: various scendicos. Il 


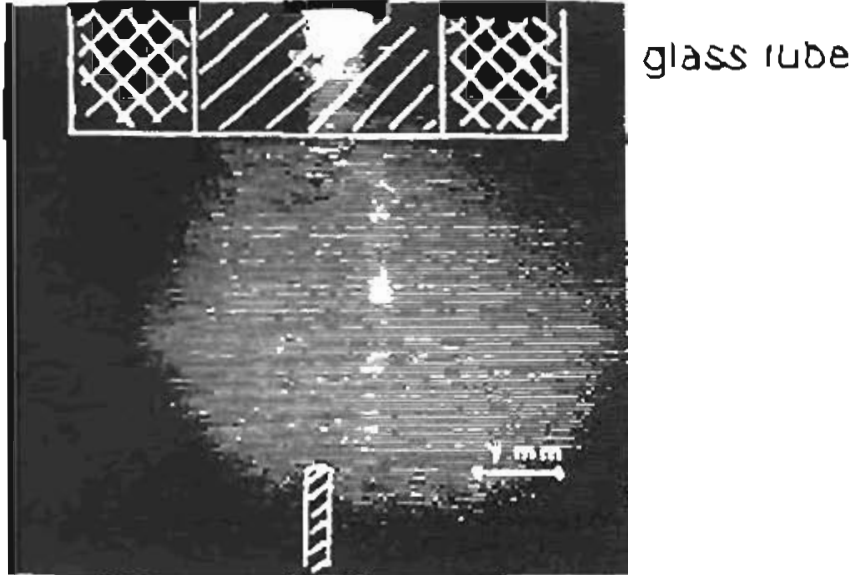

anode tip

Fig.6. Tiset al a single riubrislection bubble moung liom th:

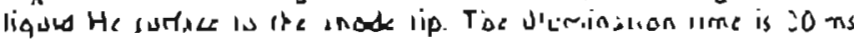

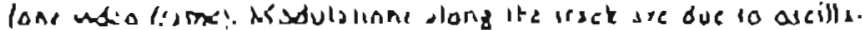

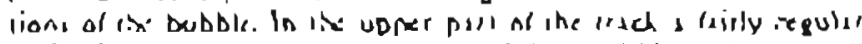

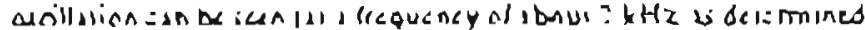

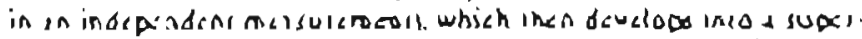

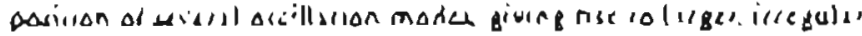
ipascigs

we consider a mulsizicciran bubble being a:keged. e $B$

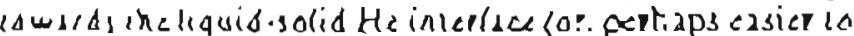
1salere. inc incelace belween liquid He $1.1 d$ solid hydrogta1. "I mighe dusinteg/zle ineo individ:al singlezlezeroa bubbles. cruscd by the delormarica ol ine large bioble when $\mathrm{ll}$ is in caneze wish bae salid. "f ine percurbzcian genelded by ite soled wall is small snaugh. on the ocher As $A d$, ihe mullielecesan bubble cauld remain siable, and $\Delta$ cauld in etis way have a conventent icap lo study

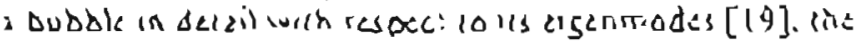

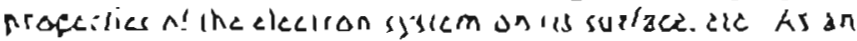
ideresising as ace of the mulicledion bubbles she elecsion densily $\Delta A$ i hes surface can be rarher large, well beyond ihe limil al $7 . i^{2} 10^{4} \mathrm{~cm}^{-1}$ (J) on a hal liaund He surface guren by inc snecl of ithe chd insiability mencioned above. The inclose is asssible becoure the bubble dus is its

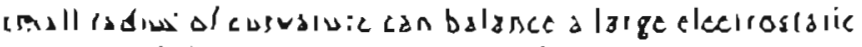
pleceule al ihe clocisan sysiem irside ll.

\subsection{Elecrons on the films}

As an alieinzirue way of curcumucnling the end irislabslily DAL UA USE ide uan der Wále lorce. aching liom s bolro warreze upana inin He flm and has siabilize the He suldace cues al very high clezlion densiluas ud 10 $10^{\prime \prime} \mathrm{c} / \mathrm{cm}$ ' and xeyond Thus rangc, where quznrum cor. recliansiolie classical betisuar ol ite 20 eleclionsysicm le expecied ra became icleuant his been demonjiraled

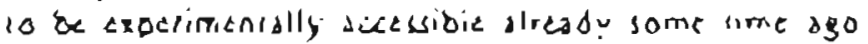

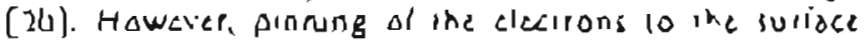
roughnas al ith salid subsitalc belaw ine He film like glas plase or polymer (aile) reduced ine eleciron mobil. lis. wheh lor a lang jime hampered the experimenls with
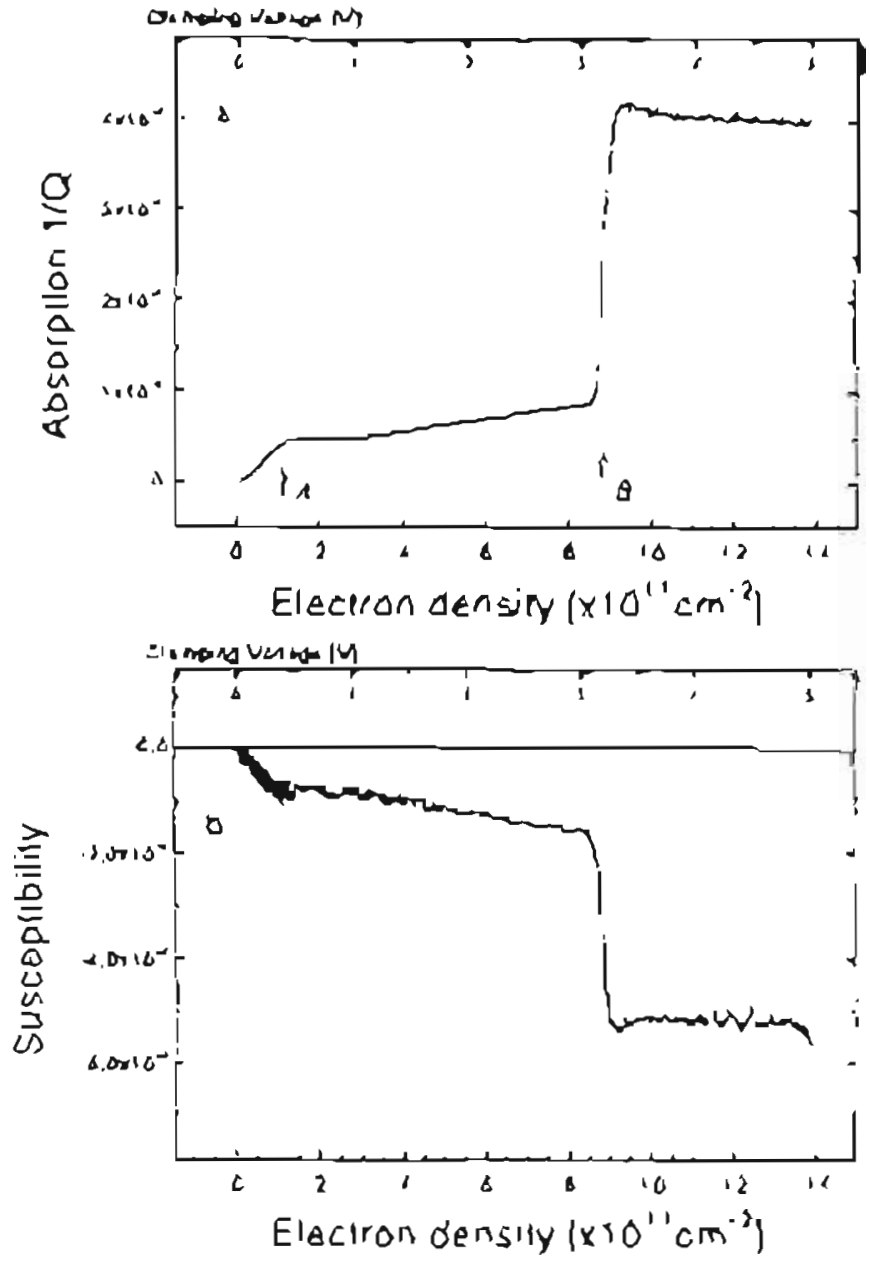

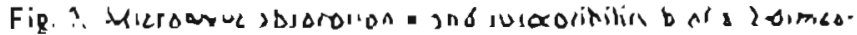

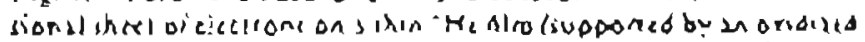

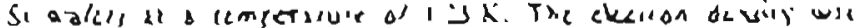

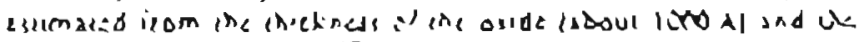

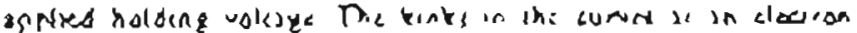

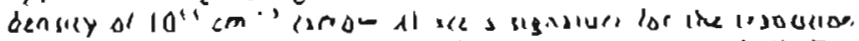

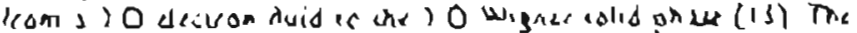

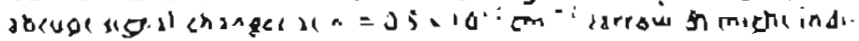

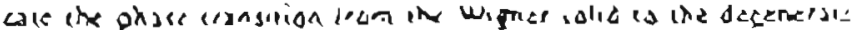
IO FCCTI As?

these syserms In ipile o: ruct difteulues mieroivave medsu-emeols have viry recently erealcd seriking (ea.

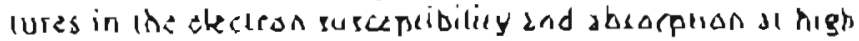
eleziron densiles lice Fig h [11]. which mighe be inter. preted as the long-iaughe phece elansition frach be big. ner cruglal in the degenefart Furmi gat in the quncum regime of a 20 Coulomb cyricm Mare delsiled erper. merses are presenily underusu is find a duransl \&udence lor such a iransilion

\section{Cooclasion}

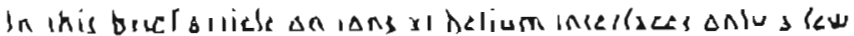

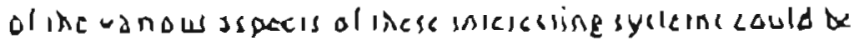

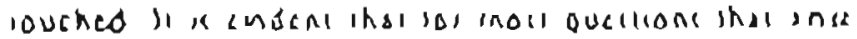


due lo the presence ol ar, inceriace only qualicallue, ll any. answers cyisl, and thal some of the plesenl argumenls ase rather speculalive. Nevertheless ithe cambinallon of ions and quanium maller inlerlaces appears as a promising and sensillue 100 io invesígale a fascinaeln: ficld al ine burderlini belueen alomic and coodensed mallel physics. These are good cbances itas cesules fram ihese sysicms, in oarreular in vicw of new experimezlal developincmes, ean serve as a usefui guideline for cheorelical efiores ioviards a more complete undersidriding ol ions in helium.

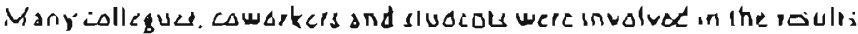
end iogecsisons pecicnled herc, and inz canirizullors of all of itrim are garcluly acknowledged Thes work was supporiodir palt by the Deucertic Foracticinsemeinschase

\section{Reicrences}

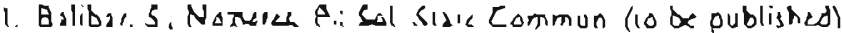

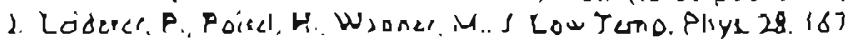

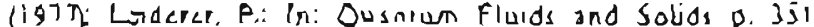
Triatiey. 5.D. asians. ED. Dulty. I w , reosi Neo York: Plenum Pres 19\%)

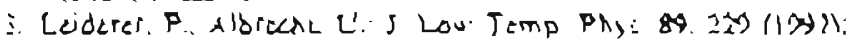

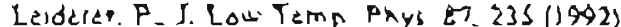

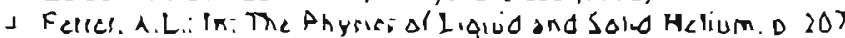
Bennemann, K H, Keriersoo. J.A. (eds) Nea Vork: Wiky $197 \mathrm{~d}$

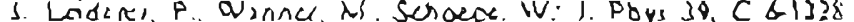
(14)8)

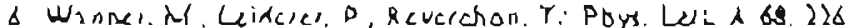
(19) B)

$\therefore$ Kuedari. M. Aadcb PR. Kcikrab.J.8: I Law Temp. Phys. I. 153110101

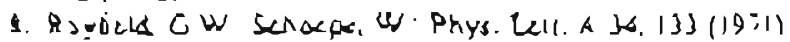

9. Golav. A.1, Mezrav.0ugin LP: Physic 19L198. 911 i(394)

10. Savignac. D. Leidurer. P. Phys. Reu La11. 49. 1869 11981)

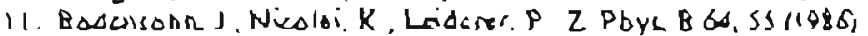

1). Balibar, S. Edwirds. D O. Livoebe. C Phys. Rev Lell al. I8) (14;9)

13. Ditum. A J. In. Prosias in La Temo Pxys val ix. Bicwer. D.F. Mulcrdin Naris Holland 198!

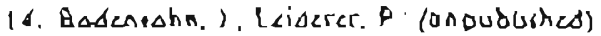

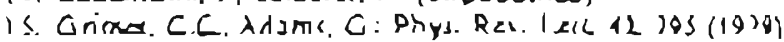

16. Kroikin. dors. I Phys C b. 1295 (19ik)

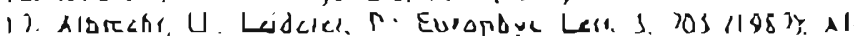

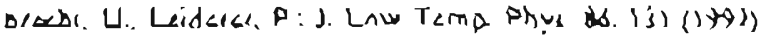

19. Lexdeict, P. Wannce. $\lambda$ Phys Lell A jJ. $180 / 19791$ Ebnci. W. Leidesas. S.: Phy Len a 80. 27$\}$ (1980)

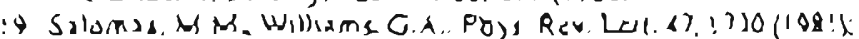
Henndsis. S.T. Gillixms. G.A. Sslomsd, M.M. In: Pracessings of the Xul insernalional Cookence on Loa Tempersiure

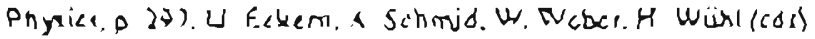
Ansiesdam. Norith Holland 19.94

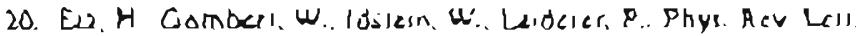
5). 2.56$)(194 \Delta)$

21 Günster. T. PXD Theni. Konsisnz. 199d 